\title{
The forked flap repair for hypospadias: The reality away from ideality
}

$\mathrm{H}$ ypospadiology is a field of paediatric urology that is rapidly expanding based on the simple fact that none of the current methods of urethroplasty has been proved superior to the others in terms of achieving the goal of excellent functional and cosmetic results. ${ }^{[1]}$

The ultimate goal of hypospadias surgery is to create a normal looking penis with a terminally situated conical meatus, to correct chordee if present and to ensure a well-directed, straight, and full urinary stream in the standing position. ${ }^{[2]}$ Hypospadias repair is one of the most challenging problems for operating surgeons due to its high complication rate. The reported incidence of complications ranges from 6 to $30 \%$ depending upon the severity of hypospadias. ${ }^{[3]}$

This study reveals the hard work of the authors towards beating the hypospadias repair challenge, yet they did not arrive at the ideal method. The authors reported no case of meatal stenosis and they did not explain why. They also failed to mention what are the methods they used to decrease the stenosis incidence. Stricture of neourethra is another complication after urethroplasty for hypospadias. The reported incidence of this complication according to different series is 6-22\%. ${ }^{[4,5]}$ The authors did not explain why they did not have such complication in their patients.

Since the authors encountered no infection in their series, their antisepsis routine and their choice of antibiotics would have been of immense use.

Patients undergoing proximal hypospadias repair are at an increased risk of complications compared to those undergoing distal repairs. After chordee release, the meatus becomes more proximal; so, the midpenile hypospadias become proximal and even pinoscrotal, but the authors did

\begin{tabular}{|l|l|}
\multicolumn{3}{c|}{ Access this article online } \\
\hline Quick Response Code: & \\
\hline
\end{tabular}

not comment on whether they either excluded those cases from this technique of repair or modified their technique in such a way to overcome the long flap needed for the neourethra.

Another issue is why the authors did not report any failed case or an ugly appearing repair. One of the interesting problems the authors did not comment upon is why they used forked flap for repair as this method is not free of the usual complications of flap such as oedema of the flap, ischaemia and even loss of the whole flap, but there is no report of such complications in this series.

One of the unanswered questions in hypospadias surgery is why some urethroplasties fail while others are successful. Surgeon's experience, operative techniques and patient factors may be involved. However, no one has a clear answer to this important question till now.

\section{Wagih Mommtaz Ghnnam}

Department of General Surgery, Mansoura Faculty of Medicine, Mansoura University, Egypt

Address for correspondence: Prof. Wagih Mommtaz Ghnnam, 14, Gawad Hosney Street, Sherbin, Dakahlia, Egypt. E-mail:wghnnam@gmail.com

\section{REFERENCES}

1. Gangopadhyay AN, Sharma S, Mongha R. Onlay preputial graft for mid and distal penile hypospadias. J India Assoc Pediatr Surg 2005;10:244-7.

2. Zaontz MR, Dean GE. Glanular hypospadias repair.Urol Clin N Am 2002;29:291-8.

3. Elbakry A. Complications of the preputial island flap tube urethroplasty. Br J Urol Int 1998;84:89-94.

4. Wienre JS, Sutherland RW, Roth DR, Gonzales ET. Comparison of on-lay and tubularized island flap of inner preputial skin for the repair of proximal hypospadias. J Urol 1997;158:1172-3.

5. Zoan IR, Sava VP, Krste DJ. Caliberation and dilation with topical corticosteroid in the treatment of stenosis of neourethral meatus after hypospadias repair. Br J Urol Int 2005;96:166-8.

How to cite this article: Ghnnam WM. The forked flap repair for hypospadias: The reality away from ideality. Indian J Plast Surg 2012;45:521.

Source of Support: Nil, Conflict of Interest: None declared. 